\title{
Spatial Analysis of Road Traffic Crashes in Oyo State of Nigeria
}

\author{
Grace O. Korter ${ }^{1}$, Olusanya E. Olubusoye ${ }^{1} \&$ Afees A.Salisu ${ }^{2}$ \\ ${ }^{1}$ Department of Statistics, University of Ibadan, Nigeria \\ ${ }^{2}$ Department of Economics, University of Ibadan, Nigeria \\ Correspondence: Grace O. Korter, Department of Statistics, University of Ibadan, Nigeria. Tel: \\ 234-80-5595-9496. E-mail:kortergrace@gmail.com
}

Received: May 13, 2014 Accepted: June 4, 2014 Online Published: July 31, 2014

doi:10.5539/jsd.v7n4p151 URL: http://dx.doi.org/10.5539/jsd.v7n4p151

\begin{abstract}
Road Traffic Crashes (RTC) are a global concern because of the frequencies of deaths, injuries and material losses experienced by countries as a result of the menace. The significance of the effect of RTC to individuals, societies and nations at large call for investigation into the pattern of the menace across neighbourhoods. This paper examined the characteristics, spatial pattern and concentrations of RTC in Nigeria, Oyo state and across Local Government Areas (LGA). Data on RTC were obtained from Federal Road Safety Commission (FRSC). The longitudes and latitudes of RTC locations were collected based on landmarks provided by FRSC. RTC cases were found to pose a greater risk of deaths than most of the diseases that is the focus of individuals, government, nongovernmental organizations and international bodies in Nigeria. The analysis showed that there was less than $1 \%$ likelihood that the observed clustering pattern in RTC could be a result of random chance. The Unique RTC center was found to be Akinyele LGA. The standard deviational ellipse was found to be a more elegant measure of spatial concentration than the standard distance deviation. The black spots include Oyo West, Oyo East, Afijio, Akinyele, Lagelu, Egbeda, Ona Ara, Oluyole, Ido, Ibadan North, Ibadan North East, Ibadan North West, Ibadan South East and Ibadan South West LGA. The results should enable the orientation of safety and injury prevention policies targeted towards reducing the frequency of RTC and deaths of young adults in the state.
\end{abstract}

Keywords: deaths, diseases, georeferencing, road traffic crashes, safety, spatial analysis

\section{Introduction}

\subsection{Introduction to the Problem}

The occurrence of Road Traffic Crashes (RTC) at close localities are a function of higher levels of traffic, which in turn are a product of higher concentration of social activities such as residential, employment or employment related namely, shopping and entertainment (Levine, Kim \& Nitz, 1995a). Every year, 1.2 million people die in road accident worldwide. Millions of others sustain injuries, with some suffering permanent disabilities. No country is spared in this toll of lives and suffering that strikes the young ones in particular. Enormous human potential is being destroyed with grave social and economic consequences. Road safety is thus a major public health issue throughout the world. Worst still, road traffic fatalities are forecast to decrease by about $30 \%$ in high income countries over the next $15-20$ years, whilst road traffic fatalities in low and middle income countries are expected to increase on an average by around $80 \%$ if current policies and practices continue without novel interventions. Furthermore, road traffic injuries cost low income and middle income countries between 1 and 2 percent of their gross national product which is more than the total development aid received by these countries (WHO, 2004).

In Nigeria, RTC death rate is 162 deaths per 100,000 populations (Ogbodo \& Nduoma, 2011). This is against the world average of 22 deaths per 100,000 populations (Sukhai, Jones, Love, \& Haynes, 2011). Thus, the Nigerian RTC death rate is disproportionately high in comparison to the world average by over 636 percent. The significance of the effect of RTC to individuals, societies and nations at large call for a succinct investigation of the menace across neighbourhoods. Thus, the objective is to examine the characteristics, spatial pattern and concentrations of RTC across Local Government Areas (LGA). Specifically the study compares the number of deaths that accrue from some selected diseases and RTC, investigates RTC occurrences by comparing the national situation with Oyo state and identifies the black spots. The results should enable the orientation of safety and injury prevention policies targeted towards reducing the frequency of RTC and deaths of young adults in the 
state.

This study assumes the existence of spill over effects across cross-sectional units. Thus the research question is whether the spatial pattern of RTC is clustered or random across the study area, that is, is there any spatial dependence of RTC events across cross sectional units. The null hypothesis states that the spatial pattern of RTC is randomly distributed across the LGA of Oyo state, Nigeria.The paper is organized in sections as follow: introduction, methods, results and lastly discussion.

\subsection{The Notion of Space}

The pinpoint concentrations of the road traffic crashes' data reveal a cross - sectional spatial pattern. The existence of a spatial interaction between contiguous road traffic crashes' pinpoint locations reveal spatial concentrations and hence suggests spatial dependence between individual road traffic crashes' occurrences. Thus, the issue of space and spatial dependence are inevitable for maximum remedial effect. Spatial dependence in a collection of sample data implies that observations at location $i$ depend on other observations at locations $j$. Formally, $y_{i}=f\left(y_{j}\right), i=1, \ldots, n j \neq i$. Note that the dependence can be among several observations, as the index $i$ can take on any value from $i=1, \ldots, n$.

In many circumstances, the most questionable assumption in cross sectional studies is that cross sectional units are mutually independent. This is not always true, and generally, spatial effects are not taken into account. The importance of spatial dependence as the fundamental concept underlying the essence of data analysis is unquestionable especially when the units of observations are geographic regions with arbitrarily drawn boundaries. Failure to take cognizance of spatial effects when they actually exist could lead to serious model misspecification. At best, ignoring spatial effects lead to inefficient least squares estimators and biased statistical inference and, at worst, to biased and inconsistent least squares estimators.

\subsection{Relevant Literature}

Levine et al. (1995a, b) employed geo - visualization, spatial analysis and a spatial lag regression to explain motor vehicle crashes for Oahu. Their study included various forms of employment activities and accounted for spatial autocorrelation between accidents at one location with accidents at other locations of the study area. The spatial units were block zones with their minor and major arterial roads. Findings were therefore, in respect of the block zones. The spatial dependence variable, as measured by an inverse distance matrix, was highly significant, indicating that crashes tend to be more clustered by block group than what would be expected by a random distribution. Then area of the block group was significant with more accidents in smaller block groups than larger ones. Financial employment and military employment were negatively related. Three of the road characteristic variables also produced positive and significant coefficients. The existence of a free way crossing a block group adds on average, 26 more accidents a year. Similarly, for every mile of major arterial in the block, there are on average about 10 more accidents per year. Free way access roads, however, were even more significant. For every additional mile of freeway access road or ramp in a block group, there were about 38 more crashes each year. Results support the notion that traffic crashes tend to follow traffic patterns in the sense that variables predicting trips also predict crashes.

Labinjo, Juillard, Kobusingye \& Hyder (2009) explored the epidemiology of road traffic injury in Nigeria and provided data on the populations affected and risk factors for road traffic injury. The road traffic injury rates for rural and urban respondents were not significantly different. Increased risk of injury was associated with male gender among those aged 18-44 years. Simple extrapolations from the survey suggested that over 4 million people may be injured and as many as 200,000 potentially killed as a result of the menace annually.

In a similar vein, Trivedi \& Rawal (2011) investigated the prevalence of major and minor road traffic accidents and the relation with driving practices among young drivers. A cross sectional study among young drivers selected from the tuition classes in Ahmedabad and Vadodara was used for the study. Results showed that prevalence road traffic accidents are high among young drivers and related to high speed of driving, use of mobile phones and not following safety measures while driving.

To reduce accidents casualties and improve safety and security on roads, usually, highway improvement project selection requires screening thousands of road segments with respect to crashes for further analysis and final selection into improvement projects. Kelle, Schneider, Raschke \& Shirazi (2013) described a two - step procedure for selecting potential accident locations for inclusion in highway improvement projects. The first step of the proposed methodology used odds against observing a given crash count, injury count, run - off road count and so on as measures of risk and a multi-criteria pre-selection technique with the objective to decrease the number of prospective improvement locations. The second step was based on a composite efficiency measure of 
estimated cost, benefit and hazard assessment under budget constraint. To demonstrate the two-step methodology, the study analyzed 4 years of accident data at 23000 locations where the final projects were selected out of several hundred of potential locations.

In order to enhance prioritization of the burden of RTC Chandran et al. (2013) calculated years of life lost and reduction in life expectancy using population and crash data from Brazil's ministries of health and transport. The potential for reduction in crash mortality was calculated for hypothetical scenarios reducing death rates to those of the best performing region and age category. For males, at birth, RTC reduced the life expectancy by 0.8 years and 0.2 years for the females. The study concluded that many years of life lost for men and women could be averted if all rates matched those of the lowest - risk region and age category.

Rancourt, Cordeau \& Laporte (2013) developed different scheduling algorithms embedded within a tabu search heuristic using a special focus on truck drivers. This was in attempt to improve safety amongst long haul carriers in vehicle routing and scheduling in the United States. The overall methods were tested and the computational results confirm the benefits of using a sophisticated scheduling procedure for long haul transportation.

More recently, Chun, Goh, Currie, Sarvi \& Logan (2014) summarized findings on road safety performance and bus-involved accidents in Melbourne along roads where bus priority measures had been applied. Results from an empirical analysis of the accident types revealed significant reduction in the proportion of accidents involving buses hitting stationary objects and vehicles, which suggests the effect of bus priority in addressing manoeuvrability issues for buses. A major implication of this research is that bus priority in Melbourne's context acts to improve road safety and should be a major consideration for road management agencies when implementing bus priority and road schemes.

\section{Method}

This section describes in detail how the study was conducted, including conceptual and operational definitions of the variables used in the study.

\subsection{Data}

2002-2006 reported cases of deaths from notifiable diseases that are the focus of individuals, government, nongovernmental organizations and international bodies were obtained (National Bureau of Statistics (NBS), 2009). These diseases include cholera, HIV/AIDS, malaria, acute poliomyelitis, measles, tuberculosis, meningitis, diarrhoea and typhoid/paratyphoid. RTC cases and casualties between 2001 and 2011 were obtained for Nigeria and Oyo State (Federal Road Safety Corps (FRSC), 2012).

RTC cases in Nigeria are broadly categorized into three, namely: fatal, serious and minor cases. When an event of RTC occurs and there is at least a record of death on the spot, such is classified as fatal. When only injuries are sustained by victims it is categorized as serious, although deaths may occur afterwards. In the event of no casualties, such is classified as minor. Summation of fatal, serious and minor cases gives the total cases for the period. Total casualties of RTC are broadly categorized into two classes, namely, number killed and injured. The number killed is the record of all deaths at the scene of RTC and not thereafter, while, the number injured indicate persons that sustained injury at the instance of RTC.

The approximate longitudes and latitudes of RTC for each LGA were estimated from the record obtained from the RS 11.3 Oyo FRSC command (FRSC, 2013). Generally, the record provides an indicative description of the locality where RTC occurred and in some cases the site was described using the nearest landmarks like filling stations, roundabouts, stores, markets, garages, institutions or road intersections. Therefore, using the nearest landmarks or locality information provided in the record together with the Google Earth image, the existing digital road network, and the knowledge of the area of study, it was easy to place points on the approximate locations where the crashes occurred. The Google Earth image was particularly helpful because it provides a photographic view of the area of study together with the associated landmarks and road networks. The geographic coordinates generated with the aid of global positioning system were subsequently exported into ArcGIS where they were plotted as point locations.

The derivation of the number of RTC in each LGA was carried out based on the lists of RTC on various road networks across unit commands in the RS11.3 Oyo FRSC sector command. The geocoded RTC points provided a good basis for the identification of each RTC location. The RS11.3 FRSC command has a number of unit commands that makes up the command, while the unit commands serve designated number of road networks across LGA in the state. Furthermore, the LGA was used to clip the road networks for each service unit and also used to clip out the number of crashes that falls within each LGA. 


\subsection{Moran's Index}

This is a global tool for spatial analysis that was developed by (Moran, 1948). The Moran's Index (I) measures spatial dependence using feature locations and attribute values. The measure evaluates whether the spatial pattern is clustered, dispersed or random and determines concentration levels. The null hypothesis states that the feature values are randomly distributed across the study area. When the $\mathrm{z}$ - score or p-value indicates statistical significance, a positive $I$ indicates tendency towards clustering while a negative $I$ indicates tendency toward dispersion.

The Moran's I statistic is structured as a Pearson product moment correlation coefficient, plus $W$, the contiguity weights matrix. $Y$ is a covariance matrix, that is, the relation between the spatial units is calculated as $\left(y_{i}-\bar{y}\right)\left(y_{j}-\bar{y}\right)$. The obtained measure is scaled by

$$
\frac{n}{\sum_{i=1}^{n} \sum_{j=1}^{n} W_{i j}}\left[\sum_{i=1}^{n}\left(y_{i}-\bar{y}\right)^{2}\right] i \neq j
$$

As a result:

$$
I=\frac{n}{\sum_{i=1}^{n} \sum_{j=1}^{n} W_{i j}} \frac{\sum_{i=1}^{n} \sum_{j=1}^{n} W_{i j}\left(y_{i}-\bar{y}\right)\left(y_{j}-\bar{y}\right)}{\sum_{i=1}^{n}\left(y_{i}-\bar{y}\right)^{2}}
$$

where $y_{i}=$ the value of variable $y$ on spatial unit $i, y=$ the mean of variable $y, n=$ the number of spatial unit, $w_{i j}=$ a weight indicating if spatial unit $i$ is connected to spatial unit $j$ (e.g. 1) or if it is not (e.g.0). The summation operators are for $i=1,2, \ldots, n$ and $j=1, \ldots, n$ in all cases.

The expected value of $I$ is

$$
E(I)=\frac{(-1)}{(n-1)}
$$

The variance of $I$ under the assumption of normally distributed data is

$$
\operatorname{Var}(I)=\frac{n^{2} s_{1}-n s_{2}+3\left(\sum_{i} \sum_{j} w_{i j}\right)^{2}}{\left(\sum_{i} \sum_{j} w_{i j}\right)^{2}\left(n^{2}-1\right)}
$$

where

$$
s_{1}=\frac{1}{2} \sum_{i} \sum_{j}\left(w_{i j}+w_{j i}\right)^{2} \text { and } s_{2}=\sum_{i}\left(\sum_{i} w_{i j}+\sum_{j} w_{j i}\right)^{2}
$$

Local Moran's I and Z - Score are given below, where $\bar{y}$ is mean value and $s^{2}$ is variance.

$$
\begin{gathered}
I_{i}=\frac{\left(y_{i}-\bar{y}\right)}{s^{2}} \sum_{j} w_{i j}\left(y_{j}-y\right) \\
Z\left(I_{i}\right)=I_{i}-E\left(I_{i}\right) / \sqrt{\operatorname{Var}\left(I_{i}\right)}
\end{gathered}
$$

When two spatial units connect, a value of 1 represents this, and if not, 0 is entered in the weight matrix. For any set of $\mathrm{n}$ spatial units of a linear route, there will be 2(n-1) joins. If the focus of the analysis is not a single linear route, but an entire network, then the connectivity of spatial units to each other may need to be identified by inspection. Once identified, a binary connection matrix of spatial units represents the presence or absence of 
connections.

\subsection{Getis and Ord Statistic}

The $\mathrm{G}$ statistics is a family of statistics that have a number of attributes that make them attractive for measuring dependence in a spatially distributed variable especially when used in conjunction with the Moran's I statistic. They deepen the knowledge of the process that give rise to spatial dependence and enhance detection of local 'pockets' of dependence that may not show up when using the global statistic (Getis \& Ord, 1992).

The Getis and Ord statistic $\mathrm{G}_{\mathrm{i}}(\mathrm{d})$ measures the degree of association that results from the concentration of weighted points (or area represented by a weighted point) and all other weighted points included within a radius of distance $d$ from the original weighted point. The basis is now

$$
\Gamma_{i}=\sum_{j} W_{i j} Y_{i j}, i \neq j
$$

We assume an area subdivided into $n$ regions, $i=1,2, \ldots, n$, where each region is identified with a point whose Cartesian coordinates are known. Each $i$ is associated with a value $y$ (a weight) taken from variable $Y$. The variable has a natural origin and is positive. The $G_{i}(d)$ statistic developed below allows for tests of hypotheses about the spatial concentration of the sum of $y$ values associated with the $j$ points within $d$ of the ith point.

$$
G_{i}(d)=\frac{\sum_{j=1}^{n} w_{i j}(d) y_{j}}{\sum_{j=1}^{n} y_{j}}
$$

where $\left(w_{i j}\right)$ is a symmetric one/zero spatial weight matrix with ones for all links defined as being within distance $d$ of a given $i$; all other links are zero including the link of point $i$ to itself. The numerator is the sum of all $y_{j}$ within $d$ of $i$ but not including $y_{i}$. The denominator is the sum of all $y_{j}$ not including $y_{i}$.

We may fix the value $y_{i}$ for the ith point and consider the set $(n-1) !$ random permutations of the remaining $y$ values at the $j$ points. Under the null hypothesis of no spatial dependence, these permutations are equally likely. That is, let $Y_{j}$ be the random variable describing the value assigned to point $j$, then

$$
\begin{aligned}
& P\left(Y_{j}=y_{r}\right)=\frac{1}{(n-1)} \\
& E\left(Y_{j}\right)=\sum_{r \neq 1} \frac{y_{r}}{(n-1)}
\end{aligned}
$$

Thus,

$$
\begin{aligned}
E\left(G_{i}\right) & =\frac{\sum_{j \neq i} w_{i j}(d) E\left(Y_{j}\right)}{\sum_{j \neq i} Y_{j}} \\
& =\frac{W_{i}}{(n-1)}
\end{aligned}
$$

where $\quad W_{i}=\sum_{j} w_{i j}(d)$ 
Similarly,

$$
E\left(G_{i}^{2}\right)=\frac{1}{\left(\sum_{j} y_{j}\right)^{2}}\left[\sum_{j} w_{i j}^{2}(d) E\left(Y_{j}^{2}\right)+\sum_{j \neq k} \sum w_{i j}(d) w_{i k}(d) E\left(Y_{j} Y_{K}\right)\right]
$$

Since,

$$
\begin{gathered}
E\left(Y_{j}^{2}\right)=\frac{\sum_{r \neq i} y_{r}^{2}}{(n-1)} \\
E\left(Y_{j} Y_{k}\right)=\frac{\sum_{r \neq s \neq i} \sum y_{r} y_{s}}{(n-1)(n-2)} \\
=\frac{\left\{\left(\sum_{r \neq i} y_{r}\right)^{2}-\sum_{r \neq i} y_{r}^{2}\right\}}{(n-1)(n-2)}
\end{gathered}
$$

Recalling, that the weights are binary $\sum_{j \neq k} \sum w_{i j} w_{i k}=W_{i}^{2}-W_{i}$

and so

$$
E\left(G_{i}^{2}\right)=\frac{1}{\left(\sum_{j} y_{j}\right)^{2}}\left\{\frac{W_{i} \sum_{j} y_{j}^{2}}{(n-1)}+\frac{W_{i}\left(W_{i}-1\right)}{(n-1)(n-2)}\left[\left(\sum_{j} y_{j}\right)^{2}-\sum_{j} y_{j}^{2}\right]\right\}
$$

Thus,

$$
\begin{gathered}
\operatorname{Var}\left(G_{i}\right)=E\left(G_{i}^{2}\right)-E^{2}\left(G_{i}\right) \\
=\frac{1}{\left(\sum_{j} y_{j}\right)^{2}}\left[\frac{W_{i}\left(n-1-W_{i}\right) \sum_{j} y_{j}^{2}}{(n-1)(n-2)}\right]+\frac{W_{i}\left(W_{i}-1\right)}{(n-1)(n-2)}-\frac{W_{i}^{2}}{(n-1)^{2}}
\end{gathered}
$$

\subsection{Geographic Distributions}

Unique locations were identified with the following parameters.

The mean center is a point constructed from the average latitude and longitude values for the input feature centroids. Often called the center of gravity, identifies the geographic center or the center of concentration for a set of features.

The standard distance deviation is similar to the way a standard deviation measures the distribution of data values around the statistical mean. The standard distance deviation provides a single summary measure of feature distribution around the mean center. It measures the degree to which features are concentrated or dispersed around the geometric mean center.

The standard deviational ellipse summarizes the spatial characteristics of geographic features namely, central tendency, dispersion and directional trends. Two standard deviations are calculated - one along a transformed axis of maximum concentration and the other along an axis which is orthogonal to the transformed axis. 


\subsection{An Overview of Methods: Summary of Procedure}

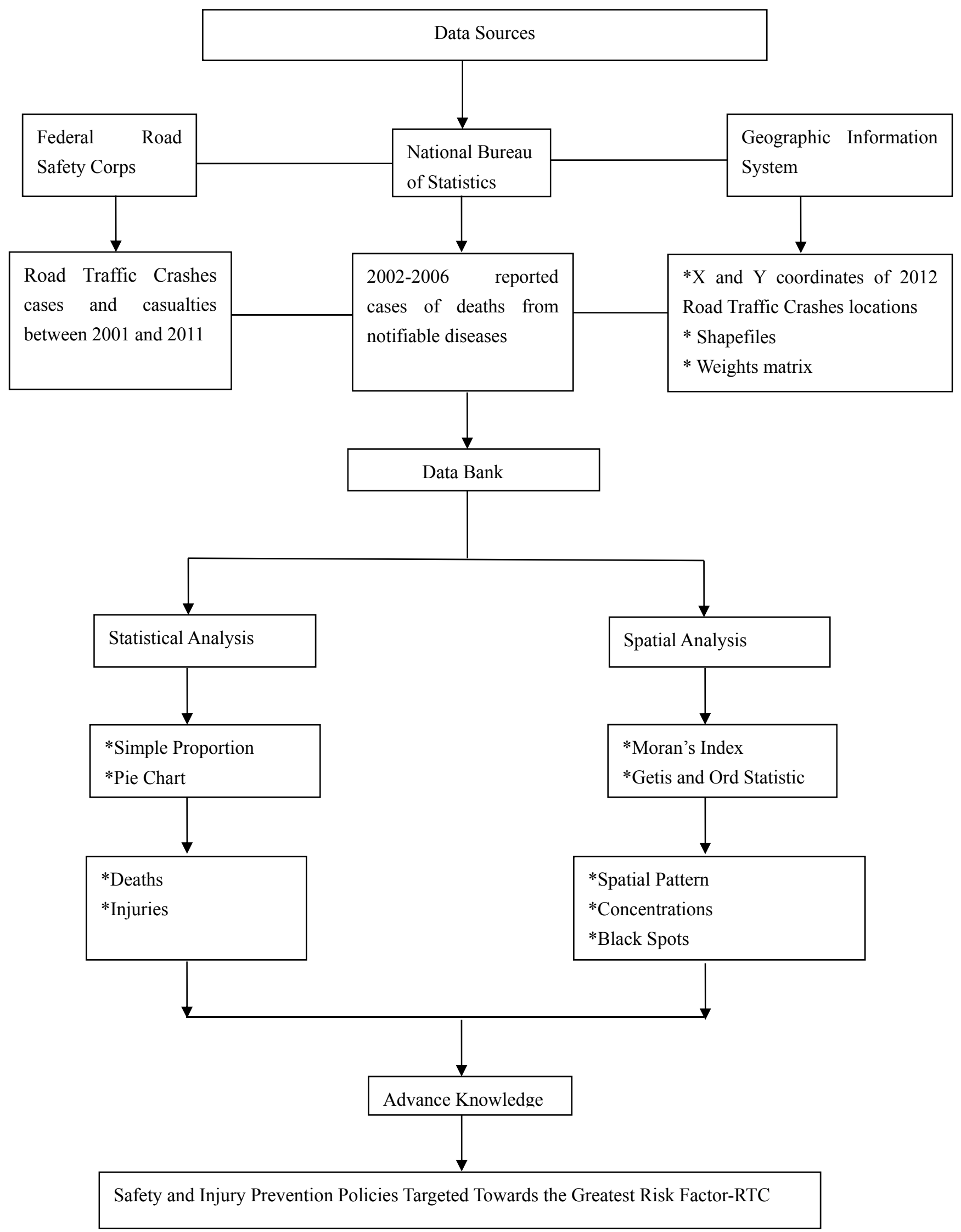




\section{Results}

This section presents the results of analysis performed on the data.

\subsection{Road Traffic Crashes: A Greater Risk Factor}

The percentage of deaths from reported cases of notifiable diseases lies between 0.04 and 10.24 percent, while, that of deaths from reported cases of RTC (accidents) is 46.73percent(see figure 1).

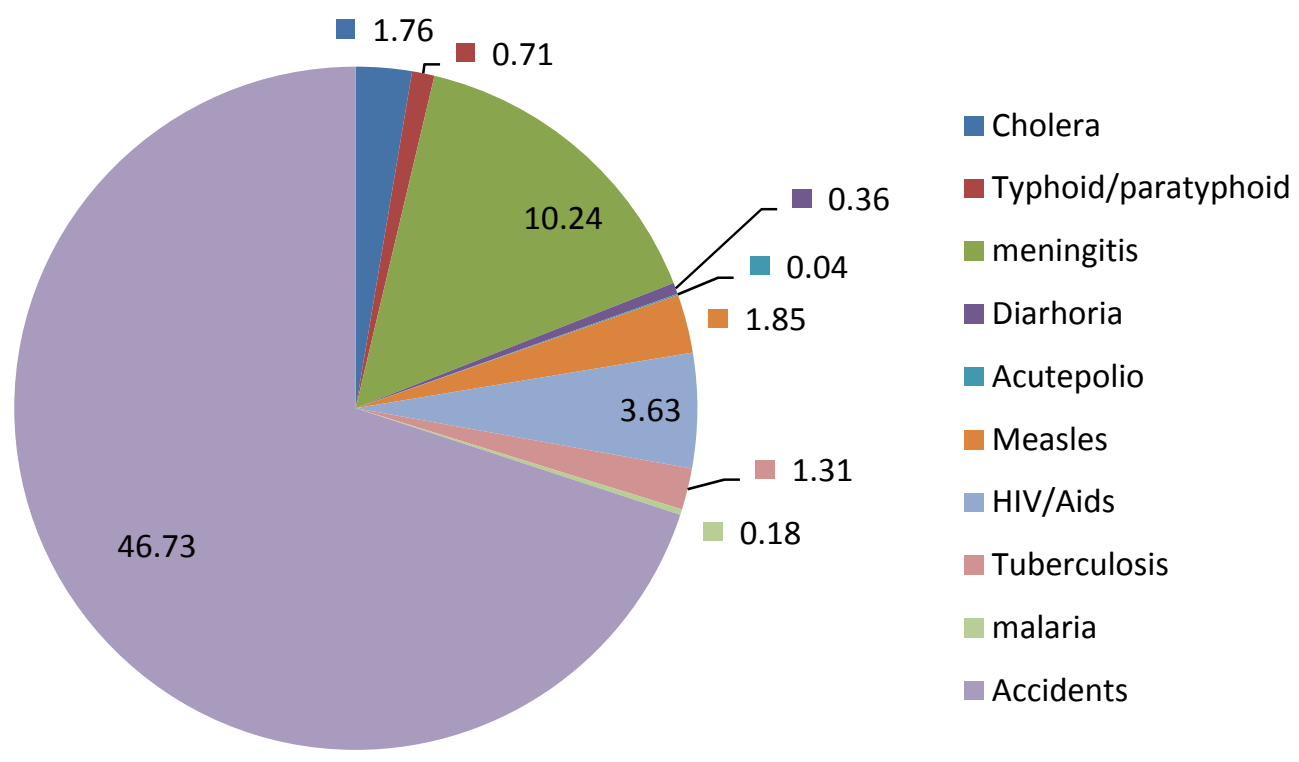

Figure 1. Percentage of deaths accruing from some notifiable diseases and RTC (Accidents)

\subsection{Road Traffic Crashes Cases in Nigeria and Oyo State}

Table 1. Represents summary statistics for RTC cases in Nigeria between 2001 and 2011

\begin{tabular}{lcccc}
\hline Cases & Fatal & Minor & Serious & Total \\
\hline Mean & 3060.64 & 2479.91 & 5609.91 & 11150.45 \\
Med & 2600.00 & 2572.00 & 5671.00 & 10854.00 \\
Max & 6966.00 & 5379.00 & 8185.00 & 20530.00 \\
Min & 1178.00 & 516.00 & 2485.00 & 4765.00 \\
STD & 1553.85 & 1417.03 & 1913.17 & 4582.66 \\
Prob & 0.080 & 0.730 & 0.720 & 0.800 \\
Sum & 33667.00 & 27279.00 & 61709.00 & 122655.00 \\
\hline
\end{tabular}


Table 2. Represents summary statistics for RTC cases in Oyo state between 2001 and 2011

\begin{tabular}{llccc}
\hline Cases & Fatal & Minor & Serious & Total \\
\hline Mean & 102.81 & 76.18 & 153.55 & 332.55 \\
Med & 72.00 & 36.00 & 109.00 & 234.00 \\
Max & 315.00 & 443.00 & 464.00 & 1222.00 \\
Min & 44.00 & 0.00 & 37.00 & 111.00 \\
STD & 77.80 & 125.09 & 127.98 & 311.80 \\
Prob & 0.002 & 0.000 & 0.089 & 0.000 \\
Sum & 1131.00 & 838.00 & 1689.00 & 3658.00 \\
\hline
\end{tabular}

In summary, of the total cases of RTC in Nigeria, 2.98\% was the result of total cases from Oyo State. $3.36 \%$, $2.74 \%$ and $3.07 \%$ constitute the proportion for fatal, serious and minor cases respectively.

\subsection{Road Traffic Crashes Casualties in Nigeria and Oyo State}

Table 3. Represents summary statistics for RTC casualties in Nigeria between 2001 and 2011

\begin{tabular}{lccc}
\hline Casualties & Number killed & Number injured & Total \\
\hline Mean & 20195.09 & 5825.73 & 26020.82 \\
Med & 18095.00 & 5351.00 & 22467.00 \\
Max & 27980.00 & 9946.00 & 34641.00 \\
Min & 15779.00 & 4065.00 & 20298.00 \\
STD & 4287.95 & 1727.35 & 5421.66 \\
Prob & 0.432 & 0.197 & 0.465 \\
Sum & 222146.00 & 64083.00 & 286229.00 \\
\hline
\end{tabular}

Table 4. Represents summary statistics for RTC casualties in Oyo state between 2001 and 2011

\begin{tabular}{lccc}
\hline Casualties & Number killed & Number injured & Total \\
\hline Mean & 759.82 & 216.73 & 976.55 \\
Med & 712.00 & 168.00 & 860.00 \\
Max & 197.00 & 439.00 & 1581.00 \\
Min & 389.00 & 97.00 & 529.00 \\
STD & 254.41 & 113.74 & 335.63 \\
Prob & 0.781 & 0.413 & 0.579 \\
Sum & 8358.00 & 2384.00 & 10742.00 \\
\hline
\end{tabular}

In a nutshell, 3.75\% of the total casualties of RTC in Nigeria constitute cases from Oyo State. $3.76 \%$ and $3.72 \%$ constitute the proportion of number injured and number killed respectively.

\subsection{Unique Locations}

The mean center for RTC distribution along with the Standard Distance Deviation (SDD) and the Standard Deviational Ellipse (SDE) is shown below. The geographic coordinates corresponding to the mean are $3.93367^{0}$ and $7.58862^{\circ}$, that is, the longitude and latitude. This implies, the mean center, that is, the center of gravity of the concentration of accidents in Oyo state is Akinyele LGA. 82.11\% of the total RTC cases were represented by the ellipse, while, $76.21 \%$ was covered by the standard distance. 


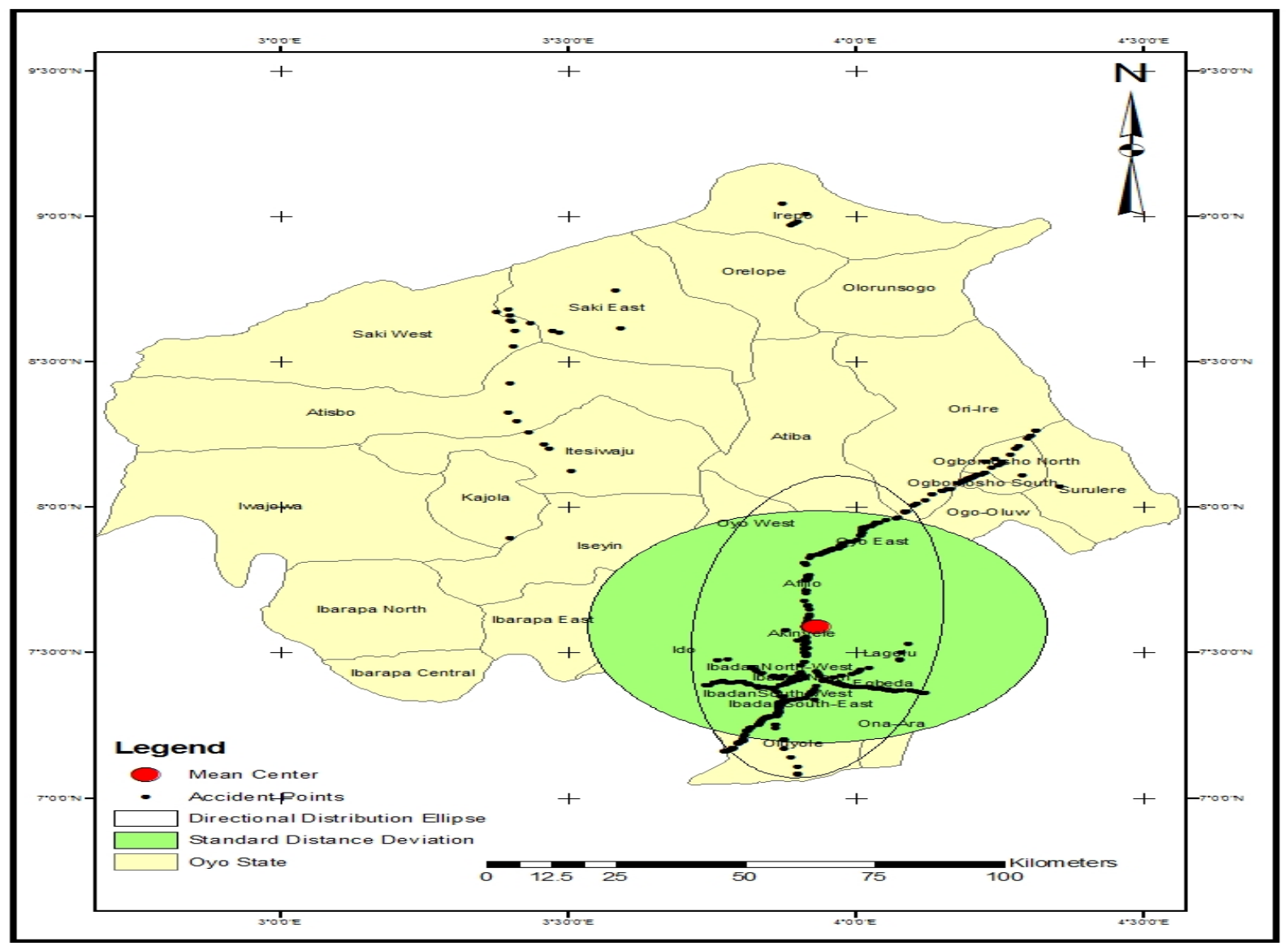

Figure 2. Representing the mean center, standard distance deviation and standard deviational ellipse of 2012 RTC in Oyo state

For the SDE, the center longitude is $3.933668^{\circ}$, the center latitude is $7.588624^{0}$, and the SDD for longitude is $0.215829^{\circ}$, while the SDD latitude is $0.520708^{0}$. The angle of rotation equal $4.7811^{0}$. The area is $4,328.952433$ per square kilometers. The SDE concisely describes the concentration in RTC locations to be within the following LGA Oyo West, Oyo East, Afijio, Akinyele, Lagelu, Egbeda, Ona Ara, Oluyole, Ido, Ibadan North, Ibadan North East, Ibadan North West, Ibadan South East and Ibadan South West.

The SDD has the center longitude to be $3.93366^{\circ}$ and the center latitude to be $7.588524^{0}$. The area is 6,090.305873 per square kilometer. The SDD gives the concentration in RTC locations to be within the following LGA Oyo West, Oyo East, Afijio, Akinyele, Lagelu, Egbeda, Ona Ara, Oluyole, Ido, Ibadan North, Ibadan North East, Ibadan North West, Ibadan South East ,Ibadan South West, Iseyin and Ibarapa East.

\subsection{Spatial Pattern and Concentration}

Moran's I equal $0.19, \mathrm{Z}$ score equal 2.61 and the $\mathrm{P}$ value equal 0.01 . The G statistic equal 0.36 with $\mathrm{Z}$ score equal 3.77 and the $P$ value equal 0.01 . The null hypothesis of randomness is rejected. There is less than $1 \%$ likelihood that this clustered pattern could be a result of random chance. Therefore, we conclude that the spatial pattern is clustered, as such; there is strong spatial dependence across the study area. 


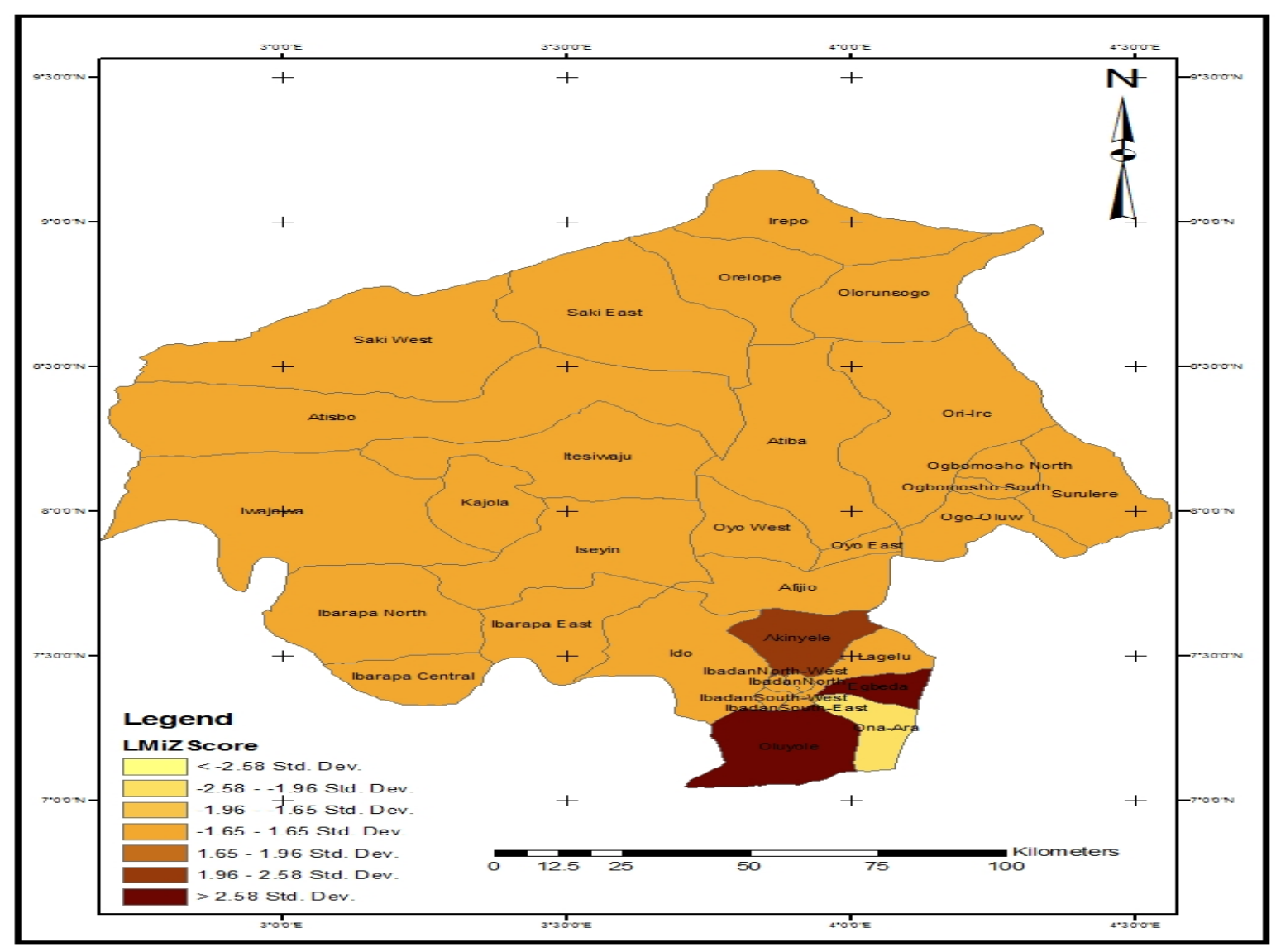

Figure 3. Showing concentration of 2012 RTC (Morans)

Table 5. Representing Moran's concentration of 2012 RTC among Local Government Areas in Oyo state

\begin{tabular}{lcccc}
\hline Local Government Area & LMiIndex & LMiZScore & LMiPvalue & Concentration \\
\hline Egbeda & +10.597 & +4.487 & 0.000 & $\mathrm{HH}$ \\
Oluyole & +7.246 & +3.385 & 0.001 & $\mathrm{HH}$ \\
Akinyele & +5.187 & +2.131 & 0.033 & $\mathrm{HH}$ \\
Ona Ara & -5.542 & -2.170 & 0.030 & $\mathrm{LH}$ \\
\hline
\end{tabular}

Result reveals high high concentration of RTC clustering within Egbeda, Oluyole and Akinyele LGA with low high concentration in Ona Ara LGA. 


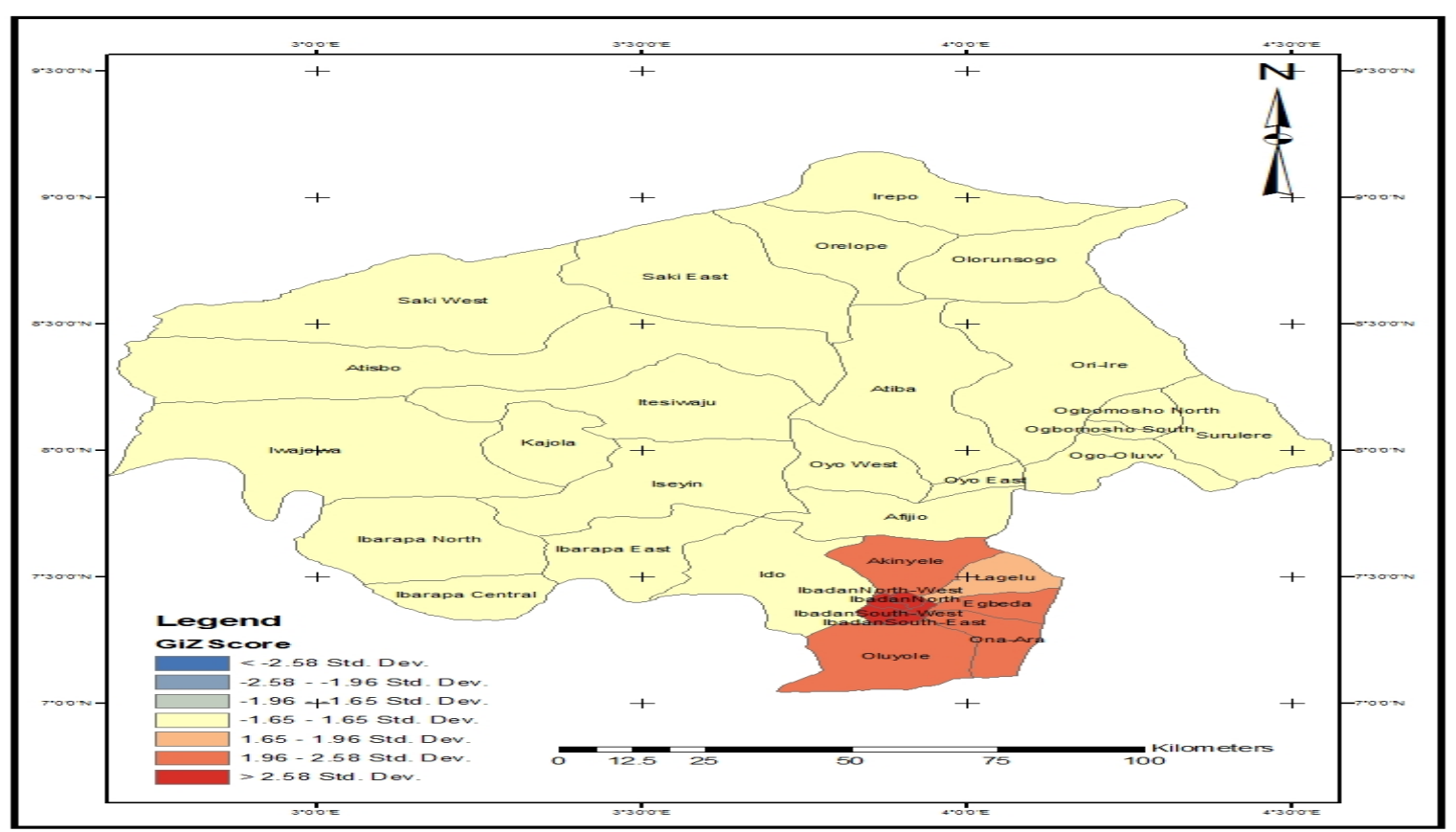

Figure 4. Showing concentration of 2012 RTC (Getis and Ord)

Table 6. Represents Getis and Ord concentration of 2012 RTC among Local Government Areas in Oyo State

\begin{tabular}{lcc}
\hline Local Government Area & $\mathrm{G}_{\mathrm{i}}$ ZScore & $\mathrm{G}_{\mathrm{i}}$ PValue \\
\hline Ibadan North & +3.00 & 0.0027 \\
INE, INW, ISE, ISW & +2.98 & 0.0029 \\
Egbeda, Ona Ara & +2.52 & 0.0117 \\
Oluyole & +2.27 & 0.0231 \\
Akinyele & +2.11 & 0.0350 \\
Afijio & +1.30 & 0.1923 \\
Oyo East & +0.84 & 0.4004 \\
\hline
\end{tabular}

The highest concentration of RTC is across Ibadan North, Ibadan North East, Ibadan North West, Ibadan South East, Ibadan South West, Egbeda, Oluyole, Ona Ara and Akinyele LGA.

Thus, the black spots include Oyo West, Oyo East, Afijio, Akinyele, Lagelu, Egbeda, Ona Ara, Oluyole, Ido, Ibadan North, Ibadan North East, Ibadan North West, Ibadan South East and Ibadan South West LGA.

\section{Discussion}

RTC pose a greater risk of deaths than all cases of notifiable diseases that is the focus of individuals, government, nongovernmental organizations and international bodies. Findings support the position of (WHO, 2004) on the high number of deaths that result from RTC in Africa. The statistics give an indication that the level of decline in total cases of RTC required to bring about a significant change in total casualties is yet to be attained for both the country and Oyo State.

Similar to the works of Levine et al. (1995a) this study identified the black spots in the state. The spatial pattern of RTC frequencies was clustered and not random across the study area. This is an indication that the likelihood of RTC in a particular location increases with the occurrence of such event in a neighbouring location. The occurrence of accidents at a geographical location affects similar occurrence at neighbouring locations across space. The extent of this spillover effect, the spatial dependence, affects the frequency of the event which leads to high or low concentration. When the spatial dependence is high, what obtains in a spatial unit is strongly related to what obtains across spatial units that are clustered Moran (1948) and Getis and Ord (1992). Thus, to 
observe a significant remedial effect, the spatial pattern must be determined. For instance, safety and security measures will best be implemented across spatial units with the same level of concentration.

Although, findings are limited to Oyo state of Nigeria; however, this study serves as a model for RTC management to guide governments, road maintenance agencies, road users, business owners, stakeholders and the public to identify localities with higher than expected likelihood of RTC. A possible catalyst to achieving the first and most important Millennium Development Goal is a reduction of RTC and RTC deaths. This could help to reduce deaths of young adults who are often the bread winners in a family. In the process extreme poverty and starvation could be significantly eradicated.

This study uses a rare combination of statistical techniques and the instrumentality of geographic information system to explain the whooping gap between proportion of deaths from RTC and some notifiable diseases in Nigeria. It shows that the focus of local and international communities should rather be highly targeted towards reducing deaths from RTC as against the present focus on diseases such as HIV/Aids and malaria. This becomes essential particularly because deaths arising from RTC is higher than deaths that result from any type of disease in Nigeria. Taking cognizance of neigbourhood characteristics the study provides the black spots for RTC occurrences across the state. Thus, the paper gives advance knowledge on the issue of RTC. This could aid planning for remedial measures that will in turn lead to significant remedial effect. Ultimately, the study provides an evidence based framework for RTC management in Oyo state that could be replicated for every other state across the country. Apparently, our findings should enable the orientation of safety and injury prevention policies targeted towards reducing deaths from RTC in the country.

\section{Acknowledgments}

Our gratitude goes to the Federal Road Safety Corps (FRSC). Federal Republic of Nigeria. RS11.3 Oyo Sector Command. We acknowledge contributions from participants at the June, 2013 Faculty of Science International conference on Science and sustainable development in Nigeria, University of Ibadan, Ibadan, Nigeria. This work is the result of the joint efforts of the authors; authors contributed equally.

\section{References}

Chandran A., Kahn G., Sousa T., Pechansky F., Bishai D. M., \& Gyder, A. A. (2013). Impact of road traffic deaths on expected years of life lost and reduction in life expectancy in Brazil. Demography, 50(1), 229-236. http://dx.doi.org/10.1007/s13524-012-0135-7

Chun, K., Goh, K., Currie G., Sarvi, M., \& Logan, D. (2014). Bus accident analysis of routes with/without bus priority. Accident Analysis \& Prevention, (65), 18-27.

Federal Road Safety Corps (FRSC). (2013). Federal Republic of Nigeria. RS11.3 Oyo Sector Command.

Federal Road Safety Corps, Federal Republic of Nigeria. (2013, March). Road traffic crashes data. Retrieved from http://www.frsc.gov.ng/road-traffic-crashes-data

Getis, A., \& Ord, J. K. (1992). The analysis of spatial association by use of distance statistics. Geographical Analysis, (24), 189-206.

Kelle, P., Schneider, H., Raschke, C., \& Shirazi, H. (2013). Highway improvement project selection by joint consideration of cost benefit and risk criteria. The Journal of the Operational Research Society, 64(3), 313-325. http://dx.doi.org/10.1057/jors.2012.55

Labinjo, M., Juillard, C., Kobusingye, O. C., \& Hyder, A. A. (2009). The burden of road traffic injuries in Nigeria: results of a population based survey. Injury Prevention, 15(3), 157-162. http://dx.doi.org/10.1136/ip.2008.020255

Levine, N., Kim, K. E., \& Nitz, L. H. (1995a). Spatial analysis of Honolulu motor vehicle crashes: I. spatial $\begin{array}{llll}\text { patterns. Accident Analysis and } & \text { 27(5), }\end{array}$ http://dx.doi.org/10.1016/0001-4575(95)00017-T

Levine, N., Kim, K. E., \& Nitz, L. H. (1995b). Spatial analysis of Honolulu motor vehicle crashes: II. zonal generators. Accident Analysis and Prevention, 27(5), 675-685. http://dx.doi.org/10.1016/0001-4575(95)00018-U

Moran, P. (1948). The interpretation of statistical maps. Journal of the Royal Statistical Society B, 10, 243-251.

National Bureau of Statistics. (2013, March). Reported Cases of Notifiable Diseases (2002-2006). Retrieved from http://www.nigerianstat.gov.ng/ext/latest_release/ssd09.pdf

Ogbodo, D., \& Nduoma, E. (2011, November 17). FRSC: Nigerian roads second worst in the world. Thisdaylive. 
Retrieved from http://www.thisdaylive.com/articles/frsc-nigerian-roads-second-worst-in-the-world/103012/

Rancourt, M., Cordeau, J., \& Laporte, G. (2013) Long -Haul Vehicle routing and scheduling with working hour rules. Transportation Science, 47(1), 81-107. http://dx.doi.org/10.1287/trsc.1120.0417

Sukhai, A., Jones, A. P., Love, B. S., \& Haynes, R. (2011). Temporal variations in road traffic fatalities in South Africa. Accident Analysis and Prevention, 43, 421-428. http://dx.doi.org/10.1016/j.aap.2010.09.012

Trivedi, A., \& Rawal, D. (2011). Prevalence of road traffic accidents and driving practices among young drivers. Healthline, 2(2), 72-75.

WHO. (2004). World report on road traffic injury prevention. Retrieved from http://whqlibdoc.who.int/publications/2004/9241562609.pdf

\section{Notes}

Note 1. Figure 1 was produced by authors using 2002-2006 National Bureau of Statistics/Federal Road Safety Commission statistics.

Note 2. $\mathrm{Med}=$ =median; $\mathrm{Max}=$ maximum; Min=minimum; $\mathrm{STD}=$ standard deviation; Prob=probability.

Note 3. HH=High High; LH=Low High.

Note 4. INE=Ibadan North East; INW=Ibadan North West; ISE=Ibadan South East; ISW-Ibadan South West.

\section{Copyrights}

Copyright for this article is retained by the author(s), with first publication rights granted to the journal.

This is an open-access article distributed under the terms and conditions of the Creative Commons Attribution license (http://creativecommons.org/licenses/by/3.0/). 